\title{
A inserção precária e a questão agrária
}

\author{
Bruno Konder Comparato
}

\section{Resumo}

Um ponto de vista bastante difundido no que diz respeito ao Movimento dos Trabalhadores Rurais Sem Terra (MST) costuma associá-los ao atraso e à exclusão. Os militantes do MST seriam, assim, os representantes do Brasil arcaico por oposição ao Brasil moderno. Uma leitura atenta da produção recente sobre o tema da exclusão, ou da inclusão precária, e da desfiliação mostra, contudo, que o MST não representa o grupo dos excluídos do campo, pelo contrário, ele constitui-se numa comunidade de indivíduos novamente incluídos na sociedade brasileira. Pois, se assim não fosse, eles não seriam recebidos como interlocutores pelos poderes públicos e não teriam suas idéias e propostas levadas a público por meio da imprensa. Longe de serem os "marchadores do atraso" como já foram rotulados pelos meios de comunicação, os militantes do MST provam que a ação política organizada pode reintegrar os esquecidos pelo progresso à sociedade brasileira.

"A emergência do movimento dos trabalhadores rurais é um dos fenômenos mais importantes da história brasileira, desmistificando toda uma tradição de suposta passividade e anomia do nosso povo. Revela um problema real gravíssimo, a incomensurável miséria do campo. Pois ninguém, por grande agitador que seja, é capaz de levar dezenas de milhares de pessoas à ação organizada, a fazer homens e mulheres afrontar a brutalidade de jagunços e policiais até o sacrifício da vida, se não houver por trás muito desespero e sofrimento". ${ }^{1}$ Essa afirmação

1 Ricupero, R. "Cupins e Caifases". In: Ricupero, R. O Ponto Ótimo da Crise. 
de Rubens Ricupero sobre o movimento dos trabalhadores rurais sem terra é interessante, pois evidencia dois aspectos da exclusão, ou da inclusão precária, a que são submetidas as classes trabalhadoras no Brasil. Com efeito, é possível considerar a questão a partir de dois pontos de vista distintos. De um lado, há uma longa história de exclusão deliberada organizada pelos detentores do poder, de maneira a silenciar a fala dos mais oprimidos e a impedir que eles participem das decisões políticas. Daí a tradição de suposta passividade e anomia do nosso povo, de que fala Ricupero. Do outro lado, há uma conscientização crescente, da parte dos mais desvalidos, do estado de exclusão a que são relegados, devido às condições cada vez mais difíceis que precisam enfrentar para sobreviver. No caso dos trabalhadores rurais, trata-se da constatação da "incomensurável miséria do campo".

Está aí delineado o plano dessa discussão. Num primeiro momento, serão investigadas as estratégias de exclusão da classe menos privilegiada por parte dos donos do poder. Num segundo momento, a atenção será concentrada na deterioração dos meios de sobrevivência, como conseqüência do modelo econômico adotado, e nas dificuldades crescentes que isso acarreta para a inclusão dos que se situam à margem do progresso. O ponto de referência utilizado nas análises é a situação dos trabalhadores rurais, sobretudo dos que foram expulsos de suas terras, ou que a elas nunca tiveram acesso, e as respostas que o Movimento dos Trabalhadores Rurais sem Terra (MST) tem a oferecer. Mais do que representar uma solução, as alternativas propostas pelo MST expõem o equilíbrio precário em que se assenta a sociedade brasileira contemporânea.

\section{A liberdade limitada}

Enquanto o trabalho for cativo, a terra pode ser livre, mas a partir do momento em que o trabalho é livre, a terra tem que ser cativa.

José de Souza Martins ${ }^{2}$

Esse aparente paradoxo a que alude José de Souza Martins ilustra bem as limitações que podem esconder os princípios liberais e a

2 Martins, José de Souza. O cativeiro da terra. 
noção de democracia mínima. Trata-se de um paradoxo apenas aparente, porque ele nada mais faz do que reafirmar um pressuposto básico do capitalismo, que é a expropriação dos trabalhadores. No caso da escravidão, a expropriação é prévia e se faz pela impossibilidade, para o cativo, de trabalhar para si próprio. Uma vez abolida a escravidão, a expropriação do principal instrumento de trabalho, a terra, tem o mesmo efeito. A liberdade é, sem dúvida, um avanço enorme para os cativos. Pode-se até dizer que ela constitui uma conquista inestimável. Apenas a liberdade, contudo, não leva muito longe. Maria Sylvia de Carvalho Franco fala do conjunto de homens livres que, nos tempos coloniais e no Império, vagavam sem rumo e sem razão de ser: "formou-se um conjunto de homens livres e expropriados que não conhecem os rigores do trabalho forçado e não se proletarizam. Formou-se, antes, uma ralé que cresceu e vagou ao longo de quatro séculos: homens a rigor dispensáveis, desvinculados dos processos essenciais da sociedade. A agricultura baseada na escravidão simultaneamente abria espaço para sua existência e os deixava sem razão de ser". ${ }^{3}$

O paralelo com a definição mínima de democracia, de acordo com o pensamento de Norberto Bobbio, é interessante. Em O futuro da democracia, Bobbio sugere, como essa definição mínima, que "por regime democrático entende-se primariamente um conjunto de regras de procedimento para a formação de decisões coletivas, em que está prevista e facilitada a participação mais ampla possível dos interessados". Ao privilegiar o governo das leis ao governo dos homens, Bobbio afirma não ser possível pensar a democracia sem essas regras do jogo. "É pouco provável", diz ele, "que um estado não liberal possa assegurar um correto funcionamento da democracia, e de outra parte é pouco provável que um estado não democrático seja capaz de garantir as liberdades fundamentais". Mais concretamente, essas regras mínimas são três. A primeira atribui a um elevado número de cidadãos o direito de participar direta ou indiretamente da tomada de decisões coletivas. A segunda estabelece um conjunto de procedimentos, como a regra da maioria, para que seja possível tomar decisões coletivamente. Por fim, de acordo com a terceira regra, "é preciso que aqueles que são chama-

3 Franco, Maria Sylvia de Carvalho. Os homens livres na ordem escravocrata, citado em KowARICK, Lúcio, Trabalho e vadiagem - A origem do trabalho livre no Brasil. 
dos a decidir ou a eleger os que deverão decidir sejam colocados diante de alternativas reais e postos em condição de poder escolher entre uma e outra", nas palavras do autor.

Feitas estas considerações, Bobbio reconhece a sua limitação e, como que a antecipar as críticas mais plausíveis, afirma que o governo das leis é uma definição básica, mas incompleta. A solução por ele apresentada é aumentar os espaços onde se exerce a democracia. Após a instauração e generalização do sufrágio universal, não é mais possível tornar as decisões mais democráticas aumentando o número de votantes, pois o problema, hoje em dia, não é mais quem vota, mas onde se vota. Assim, ele deposita toda a sua esperança na ampliação da democracia a dois espaços fundamentais: a empresa e a administração pública. Trata-se, sustenta ele, de transformar a democracia política em democracia social. Em suma, Bobbio busca ampliar os espaços de negociação. A liberdade, contudo, permanece o objetivo maior a ser alcançado: "Não escondo de mim mesmo que o balancete de nossa geração foi desastroso. Perseguimos as 'seduções alcinescas' de Justiça e Liberdade; obtivemos muito pouca justiça e talvez estejamos perdendo a liberdade". ${ }^{4}$

Na sua principal crítica a Bobbio, Perry Anderson lembra que a democratização verdadeira só se dá com o processo de expropriação. Mas ele não é o único a criticá-lo. Com efeito, Alain Touraine também considera que a democracia não são apenas regras, se for isso, é muito pouco. Touraine considera até que não é sábio limitar a democracia a um conjunto de regras, pois "se a democracia é apenas um conjunto de regras e de procedimentos", questiona ele, "porque os cidadãos a defenderiam ativamente? Somente alguns deputados são capazes de se matar por uma lei eleitoral". ${ }^{5}$

Para Touraine é preciso ir além da observação das regras, e se interrogar sobre o conteúdo social e cultural da democracia atual, pois "agora que recuam os regimes autoritários e que desapareceram as democracias populares que nada mais eram que ditaduras exercidas por um partido único sobre um povo, não podemos mais nos contentar com garantias constitucionais e jurídicas, ao passo que a vida econômica e social permaneceria dominada por oligarquias cada vez mais

4 Anderson, Perry. "As afinidades de Norberto Bobbio".

5 Touraine, Alain. Qu'est-ce que la démocratie? 
inatingiveis". Touraine considera que o verdadeiro problema do século vinte europeu não é a miséria, mas o totalitarismo exemplificado pelo nazi-fascismo. A democracia não é só participação, é também liberação, ou ainda, é uma aposta na capacidade emancipatória do ser humano. O fundamental, portanto, é que haja uma cultura democrática que valorize o reconhecimento do outro e da alteridade. Trata-se, assim, não somente de enxergar essas diferenças, mas também de aceitálas e permitir que os outros tenham direito a essa diferença. Por essa razão é que a regra da maioria é insuficiente, e o autor insiste na necessidade de encontrar um meio termo entre a democracia procedimental $e$ a democracia participativa.

No seu trabalho intitulado Qu'est-ce que la démocratie?, Touraine explicita quais são, para ele, os perigos da democracia. Em primeiro lugar vem o poder econômico, representado pela economia de mercado que destrói a solidariedade entre as pessoas. Na opinião do autor, trata-se de um mercado destruidor que, de uma forma ou de outra, precisa ser controlado. Em segundo lugar vêm as revoluções que, como Saturno, sempre acabam por devorar os seus filhos, e que Touraine identifica ao perigo do Estado mobilizador. Em terceiro posto, o autor coloca o comunitarismo, o recuo sobre si mesmo ou para a comunidade, na qual os valores são voltados para dentro, e não para fora. Por fim, o quarto perigo da democracia, para Touraine, seria constituído pelo consumismo político que gera uma apatia, ou uma inércia, por parte dos cidadãos e acaba por induzi-los a concordar com o sistema político. Não há, portanto, uma definição de democracia dada de forma sistemática. Há valores, cultura, instituições, em que o principal é o reconhecimento da diferença, ou o direito à diferença. Esse é o ponto desse livro, pensado a partir de, e para, a experiência européia, mas que interessa aos leitores brasileiros pois essa proposta de reconhecimento do outro faz muito sentido para nós. Com efeito, a questão do outro é muito importante, e pode-se até dizer que tem um aspecto estratégico para a sociedade brasileira, marcada por hábitos de baixo civismo e muita incivilidade.

Talvez a fórmula mais lapidar sobre o tema do reconhecimento do outro seja aquela cunhada por Hannah Arendt: "ter direito a ter direitos". Não basta, ensina Arendt, reconhecer a existência e a diferença do outro, é preciso também aceitar que esse outro tenha os mesmos direitos que nós. Não é porque é diferente que ele deve ser tratado 
de outro modo. Essa autora procura recuperar o ideal democrático dos antigos ao revalorizar a participação política e o engajamento cívico. $\mathrm{O}$ que caracteriza a condição humana é a vida ativa, e esta se realiza principalmente no espaço público, que é onde as pessoas podem ser vistas e ouvidas. ${ }^{6}$

Enquanto Hannah Arendt aposta num retorno à democracia direta, contudo, Chantal Mouffe aponta a democracia radical como a alternativa mais viável para a esquerda. O que está em questão é uma redefinição da teoria democrática. O outro passa a ser um adversário, mas que deve ser respeitado. De acordo com Chantal Mouffe, uma imagem que paira sobre as democracias atuais é a crescente marginalização de vários grupos. Por isso, a esquerda precisa de um novo horizonte, de uma redefinição, e a melhor maneira de consegui-lo é aprofundar a igualdade e a liberdade para todos. Para a autora, contudo, não se trata de negar completamente o projeto da modernidade, que estabelece um paralelo entre a democracia e o capitalismo. Na verdade, esse projeto não foi realizado. Para que a sua retomada seja viável, seria preciso recuperar a noção de direito, $e$ transformá-la de uma perspectiva individualista para um ponto de vista coletivo. Chantal Mouffe pensa em direitos exercidos coletivamente, e que pressupõem a existência dos mesmos direitos também para os outros.

O que está em jogo, portanto, e para retomar o tema da liberdade, é realizar a junção entre a liberdade dos antigos e a dos modernos. Ao mesmo tempo que aceita a crítica que o republicanismo faz ao pensamento liberal, no sentido de rejeitar o individualismo liberal que pode levar ao totalitarismo, Chantal Mouffe acredita que o republicanismo clássico é insuficiente, pois permanece inadequado para abranger a realidade atual. Uma solução possível talvez seria a noção de liberdade que inclui um ideal de participação política, que a autora vai buscar em Maquiavel. Desse debate entre a questão liberal e a questão comunitarista, surge a democracia radical, que pode ser entendida como tentativa de recomposição de uma idéia de associativismo, ou de cooperativismo. Nesse sentido, os movimentos sociais são atores privilegiados.

6 Passerin, Maurizio D'Entrèves. "Hannah Arendt and the Idea of Citizenship". In: Mouffe, C. Dimensions of Radical Democracy. 
Faz-se necessário, agora, retornar ao nosso tema inicial, que é a relação existente entre a questão agrária brasileira, representada aqui pelo MST, e esses autores que pensam sobre a exclusão a partir dos centros de poder.

A partir das reflexões de Bobbio, introduzimos a noção das regras mínimas da democracia como forma de garantir a liberdade. Formalmente, a democracia liberal e eleições para os cargos executivos e legislativos foram introduzidas no Brasil no século passado, no início do período republicano. No que diz respeito às áreas rurais, Victor Nunes Leal mostrou, no seu livro Coronelismo, Enxada e Voto, como as eleições serviam apenas para ratificar os acordos políticos que haviam sido realizados previamente, entre os coronéis locais e o governo central. Pode-se argumentar que a primeira regra mínima da democracia não era obedecida, pois o sufrágio era longe de ser universal, sendo vedado o voto às mulheres e a uma grande parcela da população masculina que não possuía título de eleitor. ${ }^{7}$ Pode-se também contestar que as alternativas diante das quais eram colocados os que eram chamados a eleger os seus representantes fossem reais. Não se pode negar, contudo, que a prática do coronelismo, da forma como foi exposta por Victor Nunes Leal, constitui uma violação clara da regra da maioria, pois a vontade da minoria constituída pelos proprietários de terras sempre prevaleceu sobre os interesses da maioria dos trabalhadores do campo. Mesmo nas eleições municipais, que, de acordo com o autor, tinham a fama de serem "renhidas e verdadeiras", por oposição às eleições estaduais e federais fraudulentas, a regra da maioria como garantia de representatividade era apenas uma ilusão. "Por virtude dessa completa inversão de papéis", explica Victor Nunes Leal, "é evidente que, em regra, os candidatos aos cargos municipais sufragados pela maioria do eleitorado não resultam de uma seleção espontânea, mas de uma escolha mais ou menos forçada. Se os candidatos ao governo municipal, que forem apoiados pelo governo estadual, são os que têm maiores oportunidades de fazer uma administração proveitosa, esse fato já predispõe decisivamente grande número de eleitores em favor do partido local governista. Em tais circunstâncias, mesmo as eleições municipais

7 No texto "Brasil: rumo ao parlamentarismo?", Bolívar Lamounier assinala que nas primeiras eleições republicanas os eleitores chegavam apenas a 3\% da população total. 
mais livres e regulares funcionarão, freqüentemente, como simples chancela de prévias nomeações governamentais. Autêntica mistificação do regime representativo". ${ }^{8}$

Pensando em termos mais atuais, o período democrático presente, que já dura pouco mais de uma década, conta com um eleitorado que hoje já representa aproximadamente dois terços da população brasileira. A organização socio-econômica do país passou por mudanças significativas. Se, nas primeiras décadas do século, que constituem o período analisado por Victor Nunes Leal, a proporção de brasileiros residentes na área rural sobrepujava a população urbana numa proporção de dois para um, atualmente a situação se inverteu e os moradores das cidades representam $81 \%$ da população brasileira. ${ }^{9}$ Apesar da grande maioria dos eleitores residir em áreas metropolitanas, a bancada ruralista, constituída pelos deputados que representam os interesses dos grandes proprietários rurais, é uma das maiores do Congresso Nacional. O poder dessa bancada foi evidenciado durante a votação da emenda constitucional que instituiu a reeleição, quando os ruralistas condicionaram o seu voto a favor da emenda ao adiamento do pagamento das dívidas dos proprietários rurais para 1999. Em 1999, essa mesma bancada ruralista negociou com o governo o apoio às reformas em troca do aumento do prazo de pagamento dessas mesmas dívidas. Por essas e outras razões, José de Souza Martins afirma que a bancada ruralista é o maior partido do Congresso. "Há cerca de 180 representantes dos chamados ruralistas na Câmara dos Deputados", diz Martins, "o que corresponde a mais de um terço dos votos. Mas, demograficamente, as elites não são um terço da população. Portanto, estão usurpando o lugar de alguém, alguém que não está lá corretamente representado, estão ocupando certamente o lugar dos pobres e dos que trabalham". ${ }^{10}$ Com efeito, os representantes de camponeses e trabalhadores rurais, no Congresso, são muito poucos. Essa realidade é, em parte, explicada pelas distorções da legislação eleitoral.

Sempre é possível argumentar que o governo das leis que Bobbio preconiza não é o modelo vigente no Brasil, em que as leis não são

8 Leal, Vitor Nunes. Coronelismo, Enxada e Voto.

9 De acordo com o Censo Demográfico 2000 realizado pelo IBGE.

10 Martins, José de Souza. "Mecanismos perversos da exclusão: a questão agrária". In: Martins, J. S. Exclusão social e a nova desigualdade. 
observadas como o deveriam ser. Mesmo que o caso não fosse esse, $e$ que as leis fossem corretamente elaboradas, sancionadas e aplicadas, contudo, as considerações de Touraine sugerem que isto seria insuficiente. De fato, os perigos para a democracia citados por este autor, constituem um obstáculo real para o desenvolvimento da democracia no Brasil. Pode-se considerar que os dois primeiros, o poder econômico do mercado, $e$ as revoluções, que o autor identifica ao estado mobilizador, são adequadamente representados pela aliança entre os empresários nacionais, o capital financeiro internacional e o estado corporativo que desempenhou um papel decisivo durante as décadas de sessenta $e$ setenta, período em que o país apresentou as maiores taxas de crescimento econômico da sua história. Ao longo dessas duas décadas de crescimento acelerado, a política de incentivos fiscais do governo militar transformou os grandes empresários nacionais em proprietários de terras. O resultado foi o aumento da concentração da propriedade agrária, seguido de dificuldades crescentes para os camponeses. Mais recentemente, a mecanização das atividades agrícolas nas grandes propriedades, com vistas a produzir um excedente exportável de produtos agrícolas, tornou inútil a mão de obra de trabalhadores rurais, até então aproveitados esporadicamente nas grandes lavouras, e acabou por os expulsar definitivamente dessas terras em número cada vez maior. Parte deles vão engrossar as fileiras do MST, mas a grande maioria vai tentar a sorte nas cidades.

Quanto ao tema do reconhecimento do outro que, tanto Touraine, quanto Hannah Arendt, associam à participação política, o resultado pode ser desastroso quando o que está em jogo são conflitos de terras. Em A geografia das lutas no campo, Ariovaldo Umbelino de Oliveira mostra que o período de redemocratização coincidiu com um recrudescimento dos conflitos de terras no Brasil, acompanhado de um aumento significativo do número de mortes no campo. "A década de 80", afirma esse autor, "apresenta o auge do crescimento do número de assassinatos no campo. Este auge coincidiu com o período de implantação do $I^{\circ}$ Plano Nacional de Reforma Agrária durante o governo da Nova República presidido por José Sarney. O número de mortos (302 pessoas) em 1986 foi quase três vezes maior que o mais alto alcançado durante o governo militar, em 1981. A primeira metade da década de 90, por sua vez, apresentou uma diminuição significativa do número de assassinatos no campo, embora continue ainda com uma média 
elevada (em torno de 50 mortos ao ano). É evidente que esta queda está relacionada ao abandono do I ${ }^{\circ}$ Plano Nacional de Reforma Agrária pelos governos que sucederam Sarney (Collor e Itamar Franco)". ${ }^{11}$ Outra explicação para essa coincidência entre o recrudescimento dos conflitos no campo e o período de redemocratização é o resultado de uma carência reprimida durante os anos do governo militar. A partir do momento em que foi possível vislumbrar possibilidades realistas de mudar a situação, os trabalhadores rurais se manifestaram, sendo, muitas vezes, recebidos à bala. Trata-se do melhor exemplo de silenciamento da palavra, para usar a expressão de Vera Telles.

Aí é que está, justamente, o interesse do MST como objeto de estudo no que diz respeito ao tema da exclusão. Com efeito, além de apresentar, desde a sua fundação, em 1979, um número baixo de mortes de seus militantes em conflitos de terras, em comparação às médias nacionais, o MST tem conseguido, cada vez mais, fazer ouvir a sua palavra.

A política agrícola do governo Fernando Henrique Cardoso consistiu em implantar na agricultura brasileira o modelo norte-americano, que privilegia as grandes propriedades produtoras de grãos para exportação, e pequenas unidades de produção, altamente especializadas e com uso intensivo de capital, integradas aos grandes complexos agroindustriais. Outra meta dessa política era reduzir a população no meio rural a $4 \%$ da população total. De acordo com essa visão, a questão agrária tende a desaparecer, pois os seus protagonistas principais serão obrigados a deixar o campo nos próximos anos. O destino dos camponeses forçados, dessa forma, a abandonar as terras que cultivam ou a desistir de qualquer pretensão de ter acesso a um pedaço de terra próprio, não interessa, pois a força de trabalho que representam se torna cada vez mais dispensável. Corre-se, dessa forma, o perigo de ver se confirmar o que Elimar Pinheiro do Nascimento chama de nova exclusão social. "O nosso processo de desenvolvimento", diz ele, "tende a produzir um novo tipo de exclusão social cujo resultado será a transformação do incluído incômodo, o pobre que alcançou o estatuto de eleitor, no excluído perigoso, desnecessário do ponto de vista da economia (não se trata mais de exército de reserva, pois não tem mais condições de ingressar no mercado de trabalho) e ameaçador, do pon-

11 Oliveira, Ariovaldo U., A geografia das lutas no campo. 
to de vista social, pois transgressor das leis. (...) O excluído moderno é, assim, um grupo social que se torna economicamente desnecessário, politicamente incômodo e socialmente ameaçador, podendo, portanto, ser fisicamente eliminado. É este último aspecto que funda a nova exclusão social". ${ }^{12}$

Dessa forma, a questão agrária não consistiria num assunto estratégico para o governo passado, que não hesitou em reprimir duramente a greve dos trabalhadores da Petrobrás, em 1995. "O governo faz prova de firmeza e intransigência", escreveu Plínio de Arruda Sampaio naquela ocasião, "unicamente em questões em que pode mostrar à comunidade financeira internacional que defende o dogma neoliberal. Eis por que reprimiu implacavelmente a greve do setor petroleiro; tratava-se de enviar à finança internacional a seguinte mensagem: 'Não tenham medo, o porto continua seguro'" ${ }^{13}$ O diagnóstico do descaso governamental no que diz respeito à questão agrária foi também exposto por João Pedro Stédile, militante do MST: "o governo FHC faz uma leitura da realidade agrária brasileira dizendo que não existe mais problema agrário na sociedade. Ora, se não existe mais problema, a grande propriedade não é empecilho para o desenvolvimento do capitalismo brasileiro, não é mais necessário fazer uma reforma agrária do tipo capitalista. Isso eles dizem com essas palavras. (...) A segunda premissa da política do governo é que o modelo econômico que está em implantação subordina completamente a nação ao capitalismo internacional. Para isso, abre o mercado para produtos de fora e entrega a economia ao domínio do capital financeiro. Hoje, a hegemonia, o centro de acumulação econômica, é o capital financeiro. Ora, nesse modelo a agricultura é marginalizada. A própria burguesia não vê mais na agricultura um centro de acumulação". ${ }^{14}$

Tem-se, então, duas realidades distintas no campo. De um lado, há as grandes plantações de culturas destinadas à exportação, mecanizadas e dispensadoras de mão de obra. Do outro lado, extensas áreas rurais são mantidas incultas, ${ }^{15}$ ou plantadas com pastagens. Alguns

12 Nascimento, Elimar Pinheiro do. "Hipóteses sobre a nova exclusão social: dos excluídos necessários aos excluídos desnecessários".

13 SAmpaIO, Plínio de Arruda. "Aux normes de la mondialisation".

14 Stedile, João Pedro \& Fernandes, Bernardo Mançano. Brava Gente.

15 Segundo dados do Incra, 60\% das terras no Brasil eram "não-produtivas" em 1992. 
argumentam que se trata de reserva de valor, mas para que essa tese fosse verdadeira, seria preciso que as terras fossem vendidas com freqüência, o que não acontece. Além do fato de que quando os juros estão altos o preço das terras diminui. Já faz uma década que os juros brasileiros têm se situado entre os mais altos do mundo, e nenhuma grande empresa ou multinacional imobilizaria um grande capital em terras, durante anos, como tem acontecido ultimamente no Brasil, se não houvesse uma perspectiva de lucro considerável em vista. Ariovaldo Umbelino de Oliveira defende a tese de que as terras desempenham um papel de reserva patrimonial, pois, no Brasil, a posse de terras ainda é a maior garantia contra empréstimos bancários. ${ }^{16}$ Em ambos os casos, portanto, sejam as terras destinadas ao cultivo para a exportação, sejam elas destinadas à garantia patrimonial, os pequenos lavradores ou trabalhadores rurais são desconsiderados. A sua sobrevivência depende de uma luta diária, inclusive por fazer valer os seus interesses e direitos.

Essa luta é empreendida com sucesso pelo MST, a partir de uma estratégia que se assemelha muito com a proposta de democracia radical de Chantal Mouffe. Com efeito, a construção da identidade desse movimento passa, conforme a tese desta autora, pelo debate, o discurso, o convencimento. A educação dos seus militantes é empreendida com o objetivo de recuperar a noção de direito, de uma perspectiva individualista para uma perspectiva da coletividade. Se a coletividade é sempre colocada em primeiro plano, contudo, isto não significa que haja uma volta ao comunitarismo, pois a comunidade é sempre considerada como parte integrante da sociedade da qual faz parte. Finalmente, não poderia haver exemplo mais emblemático, para ilustrar a crise dos partidos políticos em fazer a representação de interesses dos cidadãos, de que fala Chantal Mouffe, do que o modo como o MST faz as suas reivindicações. Esse movimento dispensa os deputados, que na teoria clássica da representação seriam os intermediários privilegiados entre os cidadãos e os governantes, ao ser recebido diretamente pelo presidente ou por seus ministros. Faz-se necessário ressaltar, contudo, que os deputados são chamados a atuar quando as negociações entre o MST e o governo chegam a um impasse.

16 Há quem sustente que o Banco do Brasil seria proprietário de 25\% das terras, no Brasil, se cobrasse as dívidas não saldadas. 
Para que essa articulação dos interesses da coletividade seja bem sucedida, contudo, é preciso que as suas vantagens sejam percebidas de forma clara. Aí é que as reflexões de Robert Castel podem ser de grande valia.

\section{A Liberdade recobrada}

O Movimento Sem Terra foi uma experiência muito boa. A realidade brasileira de hoje aprendi no Movimento. Tudo que sei devo a ele. Nunca vou esquecer isso. Ver as famílias que estavam necessitadas, passando fome na cidade, trabalhadores rurais sem emprego... e que agora estão vivendo como eu. É um grande sonho realizado... Vivendo em comunidade, tendo educação para os filhos, saúde. O mais importante é a saúde...

Marlene, Mato Grosso ${ }^{17}$

Este depoimento de uma militante do MST do Mato Grosso evidencia um aspecto fundamental dos movimentos sociais. Com efeito, freqüentemente os integrantes de um movimento se referem a este como a uma grande familia que lhes teria fornecido tudo o que a sociedade lhes teria negado. Essa constatação é importante, pois não se trata apenas de assegurar as condições materiais de sobrevivência. Muitas vezes, para os integrantes de movimentos sociais, o maior benefício está no fato de ter asseguradas as condições mínimas para que a luta pela sobrevivência se torne possível. Nessa perspectiva, o movimento social acaba por desempenhar um papel semelhante ao de um 'Estado de bem estar social'. Além da garantia das necessidades materiais, a militante Marlene conquistou, junto ao MST, educação e saúde. De acordo com a terminologia criada por Robert Castel, poderia-se dizer que se trata de uma alternativa à desfiliação. Talvez seja possível falar em refiliação.

Castel considera que 'exclusão' é um termo impreciso e perigoso, no sentido em que é atribuído a uma grande variedade de situações distintas. Além disso, etimologicamente, o termo exclusão remete para aquele que está fora, que foi banido. O termo contém uma idéia de

17 Santos, A. P., Ribeiro S. L. S. \& MEIHY, J. C. S. B. Vozes da marcha pela terra. 
negação. Para que haja, de fato, exclusão, é preciso, portanto, que existam práticas legitimadas, ou regras específicas de banimento, e, em última instância, de extermínio. Para Castel, o importante é considerar o processo que levou a esse estado das coisas, sendo que a exclusão constitui um limite. "Trata-se de tentar tomar a marginalização como um processo", diz ele, "e de compreender a situação desses indivíduos como resultado de uma dinâmica de exclusão, que se manifesta antes que ela produza efeitos completamente dessocializantes. A grande marginalidade apresenta-se, assim, ao fim de um percurso". ${ }^{18}$

Para que seja possível investigar mais detalhadamente esse processo, Castel concebe dois eixos, o do trabalho e o das relações sociais. "As situações marginais", diz ele, "aparecem ao fim de um duplo processo de desligamento: em relação ao trabalho e em relação à inserção relacional. Todo indivíduo pode ser situado com a ajuda deste duplo eixo, de uma integração pelo trabalho e de uma inserção relacional. Esquematizando bastante, distinguimos três gradações em cada um desses eixos: trabalho estável, trabalho precário, não-trabalho; inserção relacional forte, fragilidade relacional, isolamento social. Acoplando estas gradações duas a duas obtemos três zonas, ou seja, a zona de integração (trabalho estável e forte inserção relacional, que estão sempre juntos), a zona de vulnerabilidade (trabalho precário e fragilidade dos apoios relacionais), e a zona de marginalidade, que prefiro chamar de zona de desfiliação para marcar nitidamente a amplitude do duplo processo de desligamento: ausência de trabalho e isolamento relacional". ${ }^{19}$

Castel pensa, sobretudo, de acordo com a realidade francesa. Nessa perspectiva, a inserção relacional é considerada, de um lado, em função dos laços, mais ou menos fortes, que unem o indivíduo aos seus familiares e vizinhos, o que constitui a sociabilidade primária; e, do outro lado, em função do acesso à proteção social ampla e da existência de políticas públicas que amparam os velhos, os jovens, os desempregados, bem como em função de auxílios para garantir a moradia ou a renda mínima. A realidade do campo, no Brasil, é bem diferente.

18 CASTEL, Robert. "A dinâmica dos processos de marginalização: da vulnerabilidade à desfiliação".

19 Idem, ibdem. 
É possível, contudo, aplicar o modelo desenvolvido por Castel se, em primeiro lugar, a integração pelo trabalho for identificada com o acesso à terra e à capacidade de produzir os alimentos para a própria subsistência, e, em segundo lugar, a inserção relacional for medida pelos laços com familiares e vizinhos, bem como com a família expandida, na qual são compreendidos os compadres e os afilhados. Nem sempre a separação entre esses dois eixos é clara, pois trata-se de duas tramas de relações pessoais que se entrelaçam, constituindo uma rede de ajuda mútua capaz de fazer frente a situações de emergência. Ao ser expulso de suas terras, contudo, o camponês pode perder tudo, pois, muitas vezes, junto com ele os vizinhos e familiares também são expulsos das suas terras respectivas. Em seguida, a migração forçada acaba por desfazer a rede de proteção informal que substituía a inexistência de políticas sociais.

Este é o verdadeiro drama da questão agrária no Brasil. Muitas vezes os camponeses passam de uma situação estável ao total desenraizamento, sem passar por situações intermediárias. Talvez esteja aí a verdadeira força do MST. Com efeito, ao fazer parte desse movimento, indivíduos que haviam perdido tudo reencontram, ao mesmo tempo, uma ocupação que lhes permite garantir a sua subsistência $e$ a de seus familiares mais próximos, e uma nova rede de relações sociais que se assemelha muito à que ele conhecia anteriormente, pois é inspirada na agricultura familiar camponesa. Essa parece ser, também, a opinião de José de Souza Martins. "A experiência dos sem-terra que saíram da Encruzilhada Natalino, no Rio Grande do Sul, depois de conseguirem a terra", diz ele, "foi uma experiência histórica. (...) na fase inicial, eles foram capazes de estabelecer sistemas de cooperação sem interferir no processo imediato de produção. A cooperação se desenrolava em outros planos, como acontece em muitos assentamentos. Não é preciso fazer a tolice de estabelecer o trabalho coletivo em série para assegurar que os camponeses estão entrando no mundo moderno (e socialista!). Eles podem estar entrando, isso sim, no que de pior existe na produção coletiva, que é a alienação completa, mental e física. (...) Penso, pois, que é possível incorporar essa competência no mundo moderno. É o que propõe, no meu modo de ver, o Movimento dos Sem-Terra e tenta realizar nos assentamentos: a inserção desses trabalhadores numa lógica econômica mais ampla, racional, apoiada na idéia de retornos econômicos modernos e reciprocidades sociais basicamente tradicionais, 
na idéia de formas amplas de cooperação não só econômica, mas também de solidariedade comunitária revigorada. Com base, enfim, na sociabilidade gerada na partilha daquilo que não é propriamente econômico, pois é neste âmbito que as pessoas têm mais dificuldades para aceitar propostas de cooperação. (...) Além disso, a vida nos acampamentos promove uma radical experiência de ressocialização de seus membros e participantes. Neles se cria uma espécie de sociabilidade nova, o que significa que daí decorre mais do que a reivindicação da terra. O Movimento tem de abranger, portanto, mais do que o acesso à terra, algo que corresponda aos horizontes abertos por essa nova sociabilidade. É o que o Movimento propõe nesses projetos de cooperativa, de trabalho, de modernização das relações sociais. De certo modo, pode-se dizer que nessa experiência há certa reinvenção do mundo camponês em bases modernas". ${ }^{20}$ Dessa maneira, o MST proporciona uma nova forma de existência aos trabalhadores rurais expulsos de suas terras, mais digna e, por que não, cidadã. Ao aderirem ao movimento, camponeses que haviam perdido tudo reencontram uma identidade dentro de uma comunidade, caminhando, assim, da desfiliação para uma nova forma de inserção, tanto profissional, quanto social. Ao mesmo tempo, recobram uma nova forma de liberdade, a liberdade de fazerem planos com alguma esperança de vê-los se realizarem. Pois, como assinala José de Souza Martins, a pior forma de liberdade é aquela em que a terra é cativa.

\section{A liberdade que incomoda}

Por fim, pode-se dizer, a partir da análise que acabamos de fazer, que o MST não representa os grupos excluídos do campo, pelo contrário, ele constitui uma comunidade de indivíduos novamente incluídos na sociedade brasileira. Por essa razão é que seus militantes podem dialogar com o governo, ou levar as suas idéias a público por meio da imprensa, mesmo que esta lhes seja muito desfavorável e os critique com freqüência. O MST constitui, sim, o outro, mas não no sentido da exclusão ou da não participação, e sim no sentido do reconhecimento

20 Martins, José de Souza. "Mecanismos perversos da exclusão: a questão agrária". In: Martins, J. S. Exclusão social e a nova desigualdade. 
por parte da sociedade de que o movimento representa uma forma alternativa de organização social. Mesmo quando seus militantes são identificados ao que há de mais arcaico na sociedade brasileira, o que se revela é a diferença com relação à sociedade urbana $e$ industrial, $e$ não a identificação com a ralé que vagou pelo país ao longo de quatro séculos, a que se refere Maria Sylvia de Carvalho Franco. Justamente porque essa ralé, que constitui o verdadeiro contingente dos desfiliados, é muito dificilmente identificável, pois não tem cara, e não tem nome.

O correto é identificar os militantes do movimento ao "mais conseqüente movimento de modernização e ressocialização das populações do campo que já houve na história do Brasil", nas palavras de José de Souza Martins. "O Movimento dos Sem-Terra é que é o portador e o agente do moderno", diz esse autor, "porque questiona a estrutura de propriedade e por meio dela questiona a estrutura de poder: questiona a propriedade concentrada injustamente, anti-social, $e$, conseqüentemente, questiona o poder oligarquizado $e$, no fundo, antidemocrático. O Movimento é o único agente social a proclamar todos os dias que a questão agrária não é só nem predominantemente uma questão econômica. Ela é uma questão política" ${ }^{21}$ Portanto, se os militantes do Movimento dos Sem-Terra incomodam, é porque expõem o equilibrio precário em que se assenta a sociedade brasileira contemporânea. Enquanto os poderes públicos e a grande imprensa continuarem a considerá-los como desfiliados e representantes do arcaico contra o moderno, tratando-os como vadios e criminosos, que tem sido a maneira como foram tratados os desfiliados desde a época colonial, eles poderão continuar com a sua experiência, até agora bem sucedida, de reintegrar os esquecidos pelo progresso à sociedade brasileira.

\section{Referências bibliográficas}

Anderson, P. As afinidades de Norberto Bobbio. In: Novos Estudos Cebrap, n. 24, 1989.

BobBio, N. O futuro da democracia: uma defesa das regras do jogo. Rio de Janeiro: Paz e Terra, 1997.

21 MARTINS, José de Souza. "Mecanismos perversos da exclusão: a questão agrária". In: Martins, J. S. Exclusão social e a nova desigualdade. 
CASTEL, R. A dinâmica dos processos de marginalização: da vulnerabilidade à desfiliação. Caderno CRH, Salvador: UFBa, n. 1, 1987.

. As armadilhas da exclusão. In: CASTEL, R. Desigualdade e a questão social. São Paulo: Educ, 1997.

. As metamorfoses da questão social - Uma crônica do salário. Petrópolis: Vozes, 1998.

KowARICK, L. Trabalho e vadiagem - A origem do trabalho livre no Brasil. Rio de Janeiro: Paz e Terra, 1994.

Leal, V. N. Coronelismo, enxada e voto. São Paulo: Alfa-Omega, 1993.

Martins, J. S. Exclusão social e a nova desigualdade. São Paulo: Paulus, 1997. . O cativeiro da terra. São Paulo: Livraria Editora Ciências Humanas, 1979.

Mouffe, C. (Org.). Dimensions of radical democracy. London: Verso, 1995. The return of the political. London: Verso, 1993.

Oliveira, A. U. A geografia das lutas no campo. São Paulo: Contexto, 1996.

NASCIMENTO, E. P. Hipóteses sobre a nova exclusão social: dos excluídos necessários aos excluídos desnecessários. In: Caderno $C R H, 21$, jul./dez. 1994.

Ricupero, R. O ponto ótimo da crise. Rio de Janeiro: Revan, 1998.

SAmpaIO, P. A. Aux normes de la mondialisation. In: Le Monde Diplomatique, dezembro, 1995.

Santos, A. P.; Ribeiro, S. L. S.; MeiHy, J. C. S. B. Vozes da marcha pela terra. São Paulo: Loyola, 1998.

Stedile, J. P.; Fernandes, B. M. Brava gente. São Paulo: Fundação Perseu Abramo, 1999.

Telles, V. S. Questão social: Afinal, do que se trata? In: São Paulo em Perspectiva, 10(4), 1996.

TouRaINE, A. Qu'est-ce que la démocratie? Paris: Fayard, 1994. 